\title{
Co-educação ou classes mistas? indícios para a historiografia escolar (São Paulo - 1870-1930)
}

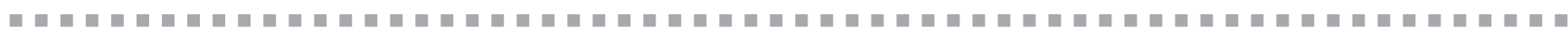
Jane Soares de Almeida

Palavras-chave: co-educação dos sexos; educação feminina.

\section{Resumo}

Examina a educação em São Paulo (1870/1930) mediante discussão sobre as classes mistas e a ambigüidade dos legisladores encarregados de se pronunciar sobre a coeducação dos sexos. Alguns defendiam tal prática, outros a condenavam usando argumentos morais voltados para os preceitos católicos, em oposição aos princípios protestantes que a introduziram primeiramente em suas escolas, o que demonstra que a separação Igreja e Estado na República recém-implantada nem sempre era uma realidade na vida cotidiana.

\section{Introdução}

Na produção educacional brasileira, obras que tratem especificamente da coeducação dos sexos, das classes mistas ou abordem uma perspectiva de gênero na historiografia não são muito comuns. No entanto, antes de adentrar no temário da co-educação e a forma como o processo foi historicamente definido no século 19 e anos iniciais do século 20 em São Paulo, tornase necessário clarificar teoricamente esse conceito.

No aspecto psicológico, a co-educação é uma forma de instruir conjuntamente, englobando as diferentes maneiras de educar; portanto, toda educação seria também co-educativa. Na terminologia pedagógica, coeducar se refere ao ato educativo no qual ambos os sexos aprendem na mesma escola, na mesma classe, nas mesmas horas e utilizando-se os mesmos métodos, as mesmas disciplinas e com os mesmos professores, todos sob uma direção comum. Na co-educação realizada de maneira intencional é colocada a exigência de cooperação entre os sexos em todas as atividades escolares e se impõe a necessidade de respeito à individualidade pessoal e sexual de cada educando, o que é também o pressuposto básico da ação educativa. Não perdendo de vista esse objetivo, meninos e meninas devem ser educados de forma a poderem desenvolver suas capacidades de maneira coerente com suas peculiaridades sexuais e opções individuais, sem a opressão exercida pela diversidade sexual, e caberia à escola co-educativa a finalidade de melhorar as relações entre os sexos de modo a colocar condições propícias para um bom relacionamento na vida adulta. 
Partindo desses princípios, é possível fazer uma diferenciação entre uma escola co-educativa e uma escola mista. A primeira visa uma existência comum entre meninos e meninas respeitando as capacidades de cada um, não havendo diferenciação quanto às potencialidades intelectuais relativas aos dois sexos; nessa visão se estabelece o princípio da igualdade na diferença, não sendo um ou outro sexo em separado que importa, mas sim o relacionamento que se constrói entre ambos, princípio base da sociabilidade e da convivência democrática. Uma escola mista pode ou não ser coeducativa, dependendo da orientação psicopedagógica adotada:

[...] una clase o el grupo coeducativo tiene peculiaridades que le diferencian del grupo unisexual o mixto, y que estas peculiaridades han de ser recogidas para elaborar una normativa que incida en toda la actividad escolar. Las materias, métodos, directrices e incluso horarios, pueden sufrir variaciones en virtud de la realidad coeducativa de que se trate. Una coeducación de ninguna manera exige la identidad para los sexos en horarios, métodos, materias e directrices (Muniz, 1970, p. 33).

A co-educação pode ser caracterizada em três formatos: co-educação total quando esta ocorre todo o tempo e as atividades escolares se organizam em regime coeducativo, atingindo a vida familiar e social, incorporando atributos de igualdade de educação e de oportunidades para os dois sexos sem distinção, plasmados por uma escola comprometida com as aspirações democráticas de uma nação. Nesse regime se vai além da simples instrução ministrada aos dois sexos em conjunto, tendo por base uma organização curricular tradicional, e se adota, juntamente com os conteúdos, posturas e procedimentos que rejeitam a desigualdade sexual e combatem os estereótipos de base naturalista. Trata-se, pois, de uma educação que contempla as relações entre os sexos e não privilegia um em detrimento do outro, nem constrói expectativas de desempenho de papéis sexuais pré-determinados. Na co-instrução as atividades se organizam de maneira apenas informativa, isto é, dizem respeito mais propriamente aos conteúdos desenvolvidos, assemelhando-se mais à escola mista, dependendo do sistema de ensino adotado. Se esse é tradicional, o contato entre os sexos é mínimo e a socialização é ainda menor, permitindo separar a classe em grupos independentes compostos por apenas um dos sexos - a presença do outro é somente física, não havendo uma verdadeira relação entre os alunos. Na co-educação parcial o regime co-educativo se concentra em algumas atividades escolares, quando o contato entre os sexos é sistemático, porém periódico. Sistemático porque faz parte de um mesmo plano de ensino e periódico porque a relação entre os dois sexos limita-se a algumas horas e a determinadas atividades, não englobando todo o tempo de permanência dos alunos na escola. Também não atenta para a identidade a ser construída entre os sexos futuramente, descuidando-se da construção de bases igualitárias quanto aos papéis a serem desempenhados socialmente.

\section{O movimento feminista internacional \\ e a co-educação dos sexos: alguns indícios}

Embora atualmente as classes mistas onde meninos e meninas são educados conjuntamente, principalmente nos países ocidentais, sejam comuns e socialmente aprovadas, a temática da co-educação dos sexos foi objeto de debates no século 19, quando colocar meninos e meninas estudando juntos nem sempre era algo visto com compreensão pelas famílias, e mereceu considerações dos vários envolvidos no processo, desde a Igreja Católica como instituição opositora do regime co-educativo aos liberais republicanos que pregavam a escola laica e universal, locus da democracia e da igualdade onde não poderia haver distinções de qualquer natureza.

O movimento feminista, que nos finais dos oitocentos ganhava força em alguns países europeus e nos Estados Unidos, redefiniria conceitos preconcebidos das menores capacidades intelectuais femininas, advogando que homens e mulheres eram idênticos em intelecto e habilidades, o que justificava a mesma educação. Porém, as feministas, os que defendiam a co-educação dos sexos e os seus detratores não diferiam quanto às expectativas do desempenho dos papéis sexuais destinados a cada sexo: depois da idade escolar, enquanto os rapazes se dirigiam para a formação profissional ou para o mercado do trabalho, as moças passavam a 
ser preparadas para a atuação no lar e para a maternidade. As feministas, ao defenderem maior liberdade e autonomia para as mulheres, também compartilhavam com liberais, positivistas e republicanos a idéia de que ser mãe era a suprema aspiração para qualquer mulher e o contrário, motivo de desgosto e frustração.

As reivindicações do movimento feminista desse período repercutiram muito brandamente no imaginário das mulheres brasileiras, e, apesar do desejo de maior liberdade e acesso à educação, assim como direito ao voto, estas ainda continuavam atreladas ao princípio ideológico que lhes colocava a maternidade como suprema aspiração e missão irrecusável. Entretanto, as grandes defensoras do sistema co-educativo nos países ocidentais foram as mulheres, notadamente aquelas que puderam ter a oportunidade de obter uma educação esmerada, embora tradicional e de acordo com os paradigmas sociais vigentes. Excluídas da escolaridade por séculos pelo fato de estarem impedidas de freqüentar escolas, destinadas em sua maioria exclusivamente ao sexo masculino, as mulheres se engajaram nas lutas por maiores direitos educacionais. As líderes feministas consideravam que a melhor forma para se alcançar a igualdade seria através de educação não diferenciada para os dois sexos, o que seria concretizado na escola coeducativa. Ressaltavam que a co-educação por si só não garantiria benefícios iguais e que a luta política por igualdade e maior liberdade deveria fazer parte da agenda reivindicatória de todas as mulheres engajadas no movimento.

Nos anos finais do século 19, Mabel Hawtrey (1896), feminista britânica, denunciava que em Londres a educação de meninas e meninos não recebia idêntico tratamento dos poderes públicos e ensino privado. ${ }^{1}$ Sua tese era a de que, se fossem ambos os sexos educados em conjunto, muitos defeitos seriam sanados na educação em geral, com o treinamento em poderes morais e psíquicos, correção do temperamento e formação de bons hábitos inerentes aos dois sexos. Para Hawtrey, a co-educação teria como objetivo ensinar as mesmas coisas a meninos e meninas, ao mesmo tempo, no mesmo lugar, pelas mesmas aptidões e métodos e sob o mesmo regime, dado que o treinamento em separado não atentava para as necessidades dos jovens e crianças, nem colaborava para seu desenvolvimento. Afirmava que na presença das meninas os meninos seriam inspirados por um grande amor e reverência, sentimentos que lhes despertavam suas mães, irmãs e mulheres em geral, e que a influência das meninas seria altamente positiva em relação aos bons modos e às emoções. Por sua vez, as meninas poderiam experienciar mais facilmente distintos modos de enfrentar a vida não limitada exclusivamente pela sociedade e restritos ao seu sexo, pois na escola estariam livres para falar com seus amigos fossem estes moças ou rapazes.

Ao defender um sistema educacional igualitário de gênero, também fazia ressalvas quanto às punições. Para Hawtrey (1896, p. 20), as meninas poderiam até mesmo sofrer castigos corporais, recebendo tratamento idêntico ao dos meninos, o que, de acordo com a orientação da Junta Escolar de Londres, seria sob a forma de uma correção moderada, utilizando-se o bambu ou vara de vidoeiro: "that moderate personal correction, whit cane or birch, should be administered indifferenthy to both sexes". Entretanto, advertia que as punições corporais, em raras circunstâncias, eram necessárias para disciplinar somente os meninos, uma vez que, para o sexo fraco, isso poderia trazer problemas variados que afetariam a saúde e o lado emocional feminino. Isso porque o efeito se faria sentir no seu sistema nervoso e ferir seus sentimentos, destruindo seus instintos femininos e impedindo o desenvolvimento do caráter. Os resultados dessa prática fariam com que a moça ou a menina ficasse exausta ou anêmica, com prejuízos para seu desenvolvimento intelectual e das funções reprodutivas, dado o organismo feminino ser diferente do masculino e seu psiquismo mais vagaroso para amadurecer. Esse ponto de vista demonstra que, apesar dos apelos da coeducação implicarem igualdade, esta se diferenciava também em alguns aspectos ao manter distinções de ordem natural e biológica que alocava ao sexo feminino atributos de fragilidade física e emocional. Mesmo os seus defensores não admitiam a continuidade da não diferenciação na esfera social quanto ao desempenho dos papéis sociais para cada sexo.

\section{A co-educação dos sexos no Brasil - vestígios historiográficos}

Nos finais do século 19, com a República, as propostas co-educativas surgidas no meio intelectual brasileiro buscavam atender ao ideal de igualdade social pela via

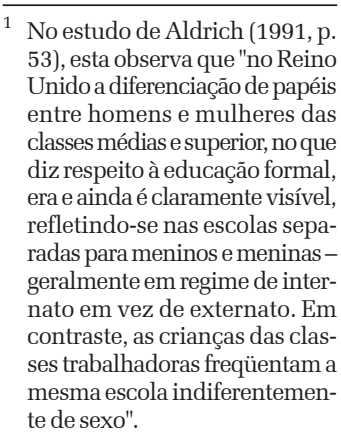


${ }^{2}$ OCongresso da Instrução do Rio de Janeiro havia sido convocado pelo conselheiro Leão Velloso, ministro do Império em 1882, o qual teria como presidente o Conde d'Eu. Em março de 1881 havia sido realizada uma conferência num salão de escola públicanaFreguesia daGlória, onde se discutiu a vantagem dese reunir um congresso de instrução e uma exposição pedagógica de vários países. No entanto, o governo da província decidiu adia a realização de ambos. Comoess atitude poderia ameaçar as relações com os países já convidados a participar os organizadores docongres fazer acontecer a exposição pedagógica por meio de donativos, 0 que foi aceito. As conferências quedeveriam serapresentadasno Congresso de Instruc̃ foram traduzidas em Atas e Pareceres em 1884. Otema da co-educação era o de número 12. (IExposição Pedagógica do Rio de Janeiro de 1883, microfilme, p. 7-28). escolar por parte dos segmentos progressistas, além de medida de economia do Estado quanto à educação popular. Nas escolas públicas paulistas e nas escolas protestantes, não era incomum que os meninos e as meninas se reunissem para instrução conjunta. Mesmo assim, havia posturas diversas quanto aos fins últimos da tarefa educativa em razão dos diferentes destinos que eram reservados para homens e mulheres no mundo social e familiar, e mesmo as escolas protestantes, que apregoavam objetivos igualitários e democráticos, também não se afastavam desse ideário, pois a sociedade brasileira não apresentava condições para implantar mudanças que realmente alterassem as expectativas sociais para ambos os sexos e os papéis que deveriam representar na vida adulta.

A visão positivista de nomear as diferenças, sem atentar para as relações entre os sexos, impedia os educadores da época de captar o verdadeiro sentido da co-educação. Esse sentido definia-se por uma visão que não poderia ser excludente, pela qual as mulheres teriam o direito de obter conhecimentos próprios do mundo público representado pela política, as esferas produtivas, o trabalho e a ciência, normalmente transmitidos apenas ao sexo masculino. A cultura e as normatizações sociais vigentes desenvolviam determinados tipos de homens e mulheres segundo sua natureza biológica, fazendo-os intérpretes dessa natureza e a transferindo para o social. Não se considerava a maleabilidade humana, as relações de poder que se edificam nas relações de gênero, nem que o meio sociocultural é o fator mais decisivamente determinante acerca das diferenças sexuais. Instalava-se assim uma ambigüidade de ordem moral e de fundo religioso que determinava ao sexo feminino funções sociais relacionadas com o ato biológico da reprodução. As mulheres eram incentivadas a serem mães e para isso convergia sua educação. Porém, deveriam manter a pureza do corpo e da alma. Essa pureza estava essencialmente ligada à sexualidade, o que reprimia e canalizava o desejo feminino apenas para a procriação.

Na esfera educativa, as propostas de ensino separado para os dois sexos traduziam uma duplicidade: expressava a aspiração social de juntar homens e mulheres por toda a vida através do matrimônio católico e compartilhar os espaços da sociabilidade e do lazer. As propostas coeducativas visavam uni-los desde a escola para poderem construir futuramente um destino em comum, porém esse mesmo destino implicaria diferentes atuações sociais, mantendo-se, pois, a mesma ordem social e cultual vigente.

Com a proximidade da República e a intensa disseminação dos ideais igualitários, o velho conceito de mundos separados para os dois sexos continuava a vigorar no panorama educacional. Nisso, a influência da Igreja Católica mais a mentalidade herdada dos tempos coloniais e ancorada na tradição portuguesa de separar os sexos desde a infância para depois juntá-los na vida adulta após o sacramento do matrimônio contribuíram para que houvesse, entre a oligarquia paulistana e nas famílias conservadoras do interior, grande resistência ao sistema de classes mistas.

Os adeptos da co-educação dos sexos, influenciados favoravelmente pelos modelos educacionais importados dos Estados Unidos e da Europa, acreditavam que juntar meninos e meninas nas escolas seria benéfico e acentuaria seus pontos positivos, preparando-os mais eficazmente para a futura vida em comum, e insistiam na sua aplicação nas escolas públicas primárias, secundárias e normais, apontando-lhe os méritos e as conveniências. Essas conveniências seriam em relação ao Estado, aos pais e aos próprios alunos, pela razão de que a freqüência nas escolas mistas produzia um estímulo apreciável para a convivência entre os sexos quanto aos costumes e maneiras, contribuindo decisivamente para amenizá-los. Esse princípio foi defendido nas Conferências Populares da Freguesia da Glória no Rio de Janeiro em 1883 e nas Atas e Pareceres do Congresso da Instrução do Rio de Janeiro, em $1884 .^{2}$

A co-educação dos sexos era a $12^{\mathrm{a}}$ questão a ser abordada no congresso. O conferencista Dr. João Barbalho Uchôa Cavalcanti, inspetor da Instrução Pública, se posiciona favoravelmente ao sistema expondo as várias razões para que este fosse implantado nas escolas públicas, valendo-se principalmente de motivos de natureza psicológica, e defende que a presença dos sexos nas escolas seria um excelente estímulo para a aprendizagem:

Com a freqüência mixta, a emulação por mais que cresça não pode chegar a odiosidade, pelo influxo benéfico que se estabelece naturalmente entre as duas divisões d'aula. Naturalmente, digo, porque, como passo a mostrar, sem esforço, sem 
trabalho do professor, os alumnos do sexo masculino aprendem a ter pelas alumnas uma certa deferencia e attenções de que é digno o sexo a que ellas pertencem. E nisso assignalo o como aproveita o ensino mixto á amenidade dos costumes (Cavalcanti, 1884, p. 3). ${ }^{3}$

Além das razões psicológicas que justificavam a introdução das classes mistas, o inspetor realiza uma ampla incursão à possibilidade de serem atribuídas exclusivamente às mulheres as aulas nas escolas primárias. Afinal, estas eram as mães e futuras mães, e as crianças, por as considerarem bondosas, cuidariam para que não se zangassem com elas no caso de apresentarem mau comportamento, e a mulher teria

[...] mais facilidade, mais geito de transmittir aos meninos os conhecimentos que lhes devem ser comunicados. Maneiras menos rudes e seccas, mais affaveis e attrahentes que os mestres, aos quais incontestavelmente vence em paciência, doçura e bondade. Nella predominam os instintos maternaes, e ninguem como ella possue o segredo de captivar a attenção de seus travessos e inquietos ouvintes, sabendo conseguir que as lições, em vez de tarefa aborrecida, tornem-se-lhes como uma diversão, um brinco. Em vez da catadura séria, inflexível do mestre, e por isso mesmo pouco sympathica ás crianças, estas encontram na professora, a graça e o mimo próprio da mulher.(...) É por isso que não falta quem entenda que o ensino e educação dos meninos pertencem de direito à mulher, chegando alguém a dizer que só por aberração e em prejuízo da infância tem sido a instrucção desta confiada ao mestre (Cavalcanti, 1884).

O conferencista argumenta que a mulher possui mais assiduidade às aulas do que os professores do sexo masculino, envolvidos em negócios e várias distrações em razão do baixo salário que recebiam. A professora, no entanto, dedica-se mais ao magistério por se identificar com a escola e sentir verdadeiro afeto maternal pelos alunos, que são sua família, e a escola poderia contribuir para a amenidade dos costumes; os pais dos alunos teriam maior economia e mais facilidade para levar os meninos e as meninas para uma só escola, em vez de ter de tomar caminhos diferentes, o que lhes ocupa demasiado tempo e esforço:
É mais fácil que um só portador conduza os alumnos, e os pais não terão necessidade de occupar nisso duas pessoas, ou de demorar os meninos e conduzil-os para outro lugar depois de terem as irmãs ido para a escola. Si as escolas tivessem de ser frequentadas unicamente por filhos de classes abastadas e ricas, não seria tanto para mencionar-se como vantagem esta de que me occupo. Mas o grande effectivo das escolas é de filhos de pessoas que não contam entre os que vivem em abastança. [...] Ora, tudo o que fôr facilitar ás famílias o enviarem os meninos á escola é uma longa vantagem que não se deve desperdiçar (Cavalcanti, 1884, p. 4).

Portanto, as vantagens das escolas para ambos os sexos, além de melhorar a instrução do povo e facilitar a vida de suas famílias, seriam um grande proveito; o Estado também ganharia em economia de recursos, motivo por si só relevante para sua adoção nas escolas brasileiras. Além dos efeitos pedagógicos, morais e econômicos do ensino misto, o governo da província ainda teria a satisfação de cumprir a incumbência constitucional de ministrar o ensino primário a todos os analfabetos e ampliar a escolaridade para mais cidadãos:

Si temos necessidade de augmentar o numero de escolas, augmento que deve ser muito considerável, para que em toda localidade haja ensino primário, o systema mixto converte-se em expediente econômico; porque, para muitos dessas localidades, desherdados de instrucção até agora, uma só escola será o bastante. Em vez de dous mestres, duas escolas, duas casas ou dous aluguéis de casa, duas mobílias, uma aula mixta presta o mesmo e melhor serviço: e com a quantia poupada da creação e custeio, que assim se tornam desnecessários, de mais outra escola, proporcionam-se os meios para em outro logar terem os meninos o preciso ensino (Cavalcanti, 1884).

Cavalcanti considera que com essas medidas o Estado poderia quase duplicar o oferecimento do ensino oficial primário, sem maiores sacrifícios para os cofres públicos e com melhor distribuição da educação elementar para todos, lamentando apenas que o governo ainda não tivesse confiado o suficiente na eficácia desse sistema por motivos que poderiam ser respeitáveis, mas que não lhe pareciam bem fundados, referindo-se às razões de ordem moral e religiosa acatadas pela maioria da

\footnotetext{
Mantive nas citações a grafia original.
} 
população. Em seguida argumenta contra os detratores da co-educação dos sexos nas classes mistas discutindo a improcedência dos motivos alegados. O principal deles seria a repugnância das famílias, fundada na desconfiança e no preconceito principalmente, classificando-os de infundados e adiantando que todas as inovações são objeto de oposição. Para evitar a resistência dos pais, sugere que haja critérios firmes nas nomeações para as escolas primárias mistas, com preferência nas mulheres para reger as classes:

Escolham-se, para estas, as melhores professoras, austeras quanto aos seus costumes, de procedimento exemplar, práticas de dirigir as crianças. Redobre o governo sua vigilancia nessas escolas. Si conhecer que a mestra, com effeito, não se mostra em condições de inspirar a mais plena confiança ás famílias, o governo apresse-se em remover a professora e confie uma tão importante missão a alguma outra mais capaz e mais apta para conseguir captar essa confiança (Cavalcanti, 1884, p. 7).

Quanto à instituição do sistema misto nas escolas normais, observa que os mesmos argumentos poderiam ser utilizados, com a diferença de que nesse nível de ensino atuariam os professores, devido ao fato deplorável de não haver professoras em número suficiente para ocupar todas as cadeiras do ensino secundário e normal. O conferencista também se refere à legislação em vigor para o ensino primário e normal da província de São Paulo que instituiu as aulas mistas nesses níveis escolares, observando que, apesar dos adversários desse sistema, não existiam assim tantos inconvenientes conforme foram vaticinados. ${ }^{4}$ Do ponto de vista da moralidade, apresenta dúvidas se colocar juntos os dois sexos nas escolas represente um perigo moral, pois, afinal, estes costumavam encontrar-se em muitos lugares que não o ambiente escolar, como nos teatros e passeios, parecendo que os seus detratores não haviam sido lembrados desse fato, acrescentando ainda que se houvesse abusos estes também se dariam em todos os lugares e não apenas nas escolas mistas:

\footnotetext{
${ }^{4}$ Para o ensino primário foi baixado o Regulamento de 27 de novembro de 1874 e para o ensino normal, o Regulamento de 5 de janeiro de 1875 , expedidos pelo desembargador Henrique Pereira de Lucena (id., p. 8).
}

\begin{abstract}
A innocencia e a honestidade certamente correm muitos perigos; mas não é na escola que mais há receial-os. Abusos podem tambem apparecer e - seguramente já se tem visto - em escolas e institutos em que não se reunem os dous sexos; e por abusos
\end{abstract}

taes não têm pedido a supressão dessas escolas e casas de educação de um só sexo! Nos collegios para um sexo sómente e até nos conventos, asylos de piedade e de virtude, tambem tem-se feito injuria ao pudor e á innocencia (Cavalcanti, 1884).

Ao se referir às capacidades cognitivas dos dois sexos, Cavalcanti (1884, p. 10) é contrário à idéia de que as meninas não poderiam acompanhar os estudos com o mesmo ritmo dos meninos e que excessos intelectuais minariam sua saúde porque, mesmo a esses, não se poderia aprofundar demasiadamente os estudos primários, o que deveria ser feito somente no ensino superior, pois "...um ensino elementar, convenientemente ministrado, não pode ir até o ponto de ter-se receio de que por causa delle adoeçam alumnos ou alumnas". No entanto, coloca uma ressalva representativa da tendência da época de considerar as mulheres menos aptas intelectualmente ao referirse ao ensino normal:

[...] não posso em verdade assegurar que em todas as matérias o aproveitamento das alumnas seja inteiramente igual ao dos alumnos; mas é certo que ellas vencem as difficuldades, e não foi preciso ainda modificar, em favor das moças, o programma que aliás contém muitas materias, pelo qual estudam os rapazes.

Seguindo um tipo de raciocínio educacional que tomava os Estados Unidos como exemplo, ainda assegura que nesse país a co-educação havia sido adotada em quase todas as escolas e que o aspecto moral da instituição do sistema misto não havia sido o determinante nessa escolha, mas sim que os debates haviam sido mais aprofundados quanto às capacidades intelectuais do sexo feminino e à identidade da instrução conjunta. $\mathrm{O}$ arrazoado termina com a exortação: "... se adopte a co-educação dos sexos, assim nas escolas primárias, como nas de ensino secundário e normal!" (Cavalcanti, 1884, p. 11).

O outro parecer, bastante sucinto, pertence ao conselheiro Dr. Theophilo das Neves Leão, que inicia seus argumentos observando que "a co-educação dos sexos implica a questão da emancipação da mulher, ente livre e inteligente, podendo viver só ou em sociedade íntima com seu companheiro natural, o homem". Apesar desse reconhecimento inicial, conclui suas observações com o argumento de que as escolas primárias e 
normais do município da corte ainda não estavam "devidamente organizadas para um nem para outro sexo" (p. 2).

Os detratores do sistema co-educativo consideram que entre os sexos há diferenças morais e intelectuais. Portanto, colocar meninos e meninas num mesmo local possibilita o risco de contaminação da pureza feminina e o perigo sempre presente de que os rapazes possam ser desviados do trabalho acadêmico pelo contato com colegas e professoras, dado que a beleza, a sedução, a garridice do outro sexo seria uma constante tentação, mesmo no vetusto ambiente escolar. Por serem intelectualmente diferentes e com aspirações de vida distintas, não tinha sentido ministrar educação igual para meninos e meninas; para as mulheres o excesso de instrução poderia prejudicar seu natural voltado mais para a emoção do que para os dotes de inteligência. Destinadas que eram para a maternidade, deveriam ser poupadas para não prejudicar a saúde dos futuros filhos, e nisso se incluía a parcimônia cognitiva.

Nos pareceres de Rui Barbosa sobre o ensino, em praticamente todas suas proposições, ele recorre aos exemplos europeus e norte-americanos para confirmar suas idéias e demonstrar que muitas delas já eram uma prática nesses países. Para o reformador, a co-educação era um sistema que já se encontrava em funcionamento nos países mais adiantados, como Estados Unidos, Suécia, Dinamarca, Suíça, Escócia, Holanda, Áustria, e mesmo no Japão. Contraditoriamente, também argumenta que no Brasil sua implantação ainda não seria aconselhável por conta da moralidade, dos bons costumes e da higiene entre os sexos, aliando-se assim, embora de forma diferenciada, aos opositores do sistema coeducativo. Quanto ao sexo feminino, Rui Barbosa observaria que a mulher não era inferior aos homens, mas seu organismo funcionava de outra forma, o que fazia que em alguns dias do mês agissem mais lentamente, precisando assim de maiores cuidados. No entanto, não opõe obstáculos a que a co-educação se efetivasse nas classes freqüentadas por crianças muito pequenas e nas escolas primárias, porém, nos graus subseqüentes, isso seria problemático, pelo menos no momento social que o País vivia.

Nas palavras de Rui Barbosa, a não indicação do sistema co-educativo nas escolas brasileiras não era uma questão pedagógica, mas de fundo moral e social. Mesmo elogiando os Estados Unidos, afirma que seria enganoso pensar que lá não havia resistências quanto ao sistema, principalmente pelo problema moral que a co-educação acarretava, e, nos limites da prudência, não seria aconselhável, por enquanto, que essa prática fosse adotada no Brasil (Barbosa, 1882, p. 26).

\section{A co-educação dos sexos em São Paulo na visão do catolicismo}

O repúdio do catolicismo à co-educação possuía uma ambigüidade moral e religiosa, e as restrições católicas em colocar juntos na mesma classe meninos e meninas, ou moças e rapazes, estavam dirigidas principalmente às classes mais favorecidas. A resistência em educar juntos meninos e meninas era um processo que atingia os católicos de todos os países. Nos Estados Unidos não havia escolas co-educacionais católicas, ${ }^{5}$ na França estas eram menosprezadas e em Portugal a Igreja era veemente em separar os sexos nas escolas, o que era compartilhado nos meios intelectuais.

Apesar do surto de progresso que a província de São Paulo atravessava no século 19 com o processo de industrialização e urbanização, diferenciando-se do restante do País em termos de desenvolvimento socioeconômico, a mentalidade católica se mantinha vinculada ao tradicionalismo, e educar as jovens era prioritariamente ensinar-lhes as prendas domésticas, religião e sociabilidade. Os demais conteúdos, embora desejáveis conforme as circunstâncias, se equilibravam em importância. Isso era válido para todas as camadas sociais, e mesmo as filhas das oligarquias paulistanas, educadas por professoras estrangeiras ou em escolas particulares, não avançavam além dessas expectativas no terreno educacional.

A oligarquia foi aliada do catolicismo ultramontano e dos limites rígidos que traçava para o sexo feminino, segundo os quais a educação não poderia transpor o espaço doméstico e educar uma menina ou uma jovem era nela projetar seu futuro como esposa e mãe. Portanto, como aceitar a idéia de educar os dois sexos segundo objetivos em comum? Como não diferenciar na escola o caminho traçado futuramente para a vida? Tal conceito, do ponto de vista religioso católico, se

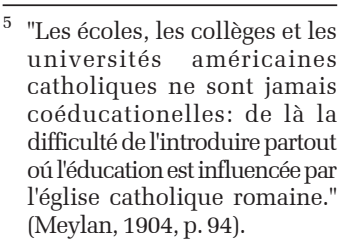

"Les écoles, les collèges et les niversités américaines tholiques ne sont jamais ducationelles: de là la oú l'éducation est influencée par (Meylan, 1904, p. 94) 
revelava inaceitável. O catolicismo conservador via na instrução feminina, por si só, uma ameaça, não desejando para suas filhas outro destino senão o de mães de família, desejo compartilhado, inclusive, pelas próprias mulheres.

Para fazer frente à ofensiva dos protestantes no campo educacional (os quais, além de introduzirem o que denominavam coeducação dos sexos, também defendiam a profissionalização e independência financeira feminina e a educação isenta de proselitismo religioso, aberta a todas as classes sociais e às diferentes raças), a Igreja Católica criaria para o sexo feminino um sistema de internatos destinados às filhas das oligarquias e da classe média que já se havia delineado no cenário social e econômico do País. Esses colégios representaram a solução para alguns problemas básicos dos católicos paulistanos: era uma proposta educativa que não atentava contra suas idéias tradicionais; não havia comprometimento com os avanços modernos que tanto os assustavam; representavam segurança para as famílias que desejavam que as filhas estudassem em bons colégios fora do seu local de residência; permitia instrução religiosa, um dos mais caros ideais familiares dos conservadores; preparavam-nas para o matrimônio e para a manutenção dos valores cristãos tradicionais; e não aceitavam a proposta de educação igual para ambos os sexos. Preservava-se, assim, a ordem social vigente e não haveria riscos sociais de se libertar a mulher pela via da instrução, mantendo-se, pois, intocados a moralidade e os bons costumes cristãos.

Os detratores do excesso de instrução para as mulheres e da co-educação dos sexos eram veementes em assinalar o perigo de lhes proporcionar demasiados conhecimentos. A profissionalização feminina e a sua ida ao mercado de trabalho, a concessão de direitos cívicos como o voto e a inserção na política eram combatidos por serem considerados fatores de desestabilização social e um atentado às recomendações religiosas. As leis naturais tinham estabelecido o lugar da mulher no lar e o dos homens na vida pública. Juntar dois seres tão diversos e com destinação tão diferente se constituía uma inobservância das leis divinas e da natureza. Subverter essa ordem seria desobedecer a Deus, e uma educação diferenciada para meninos e meninas, de acordo com a herança do passado, não poderia ter seus princípios alterados, por ser antinatural, sendo fundamental para a estabilidade social que a educação feminina fosse sempre diferente da masculina.

Os preceitos que orientavam a criação das classes mistas, mesmo se afirmando coeducativos, reproduziam também o ideal católico quanto à educação feminina de conceber as mulheres como guardiãs do lar e vocacionadas para a maternidade, o que não diferia essencialmente dos objetivos protestantes, resguardadas algumas diferenças. Os católicos, devidamente apoiados por sua igreja, viam os protestantes como representantes de um espírito de revolta contra a instituição solidamente formada no temor a Deus e no respeito à tradição cristã. Portanto, posicionamentos contrários à co-educação dos sexos, representada pela prática das classes mistas, era a atitude coerente a ser adotada pela oligarquia e pela classe média.

Embora não tenhamos encontrado vestígios da oposição da Igreja Católica em São Paulo no século 19, nas primeiras décadas do século 20 algumas pistas, como a Acta Apostólica de 1930 e as teses do Padre Leonel Franca nos anos 30/40, demonstram que a Igreja considerava a co-educação nociva e prejudicial para a boa formação cristã atacando as bases onde esta se estruturava, isto é, sobre o naturalismo e a recusa ao pecado original que legitimava a promiscuidade nessa indesejável associação dos sexos. Aceitava, porém, a educação de meninos e meninas juntos em conformidade com os lugares nos quais esses casos seriam o menor mal, alegando que em certas regiões os católicos, por serem em menor número, não teriam possibilidade de estudar em classes separadas, o que duplicaria as despesas com o ensino. Isso significava que nesses locais os jovens poderiam estudar juntos, apesar do problema religioso embutido nessa questão.

Os educadores católicos defendiam que seria possível adotar precauções que minimizassem o perigo sempre presente de colocar lado a lado seres diferentes em todos os aspectos, fossem eles físicos, intelectuais ou morais, de modo a não colocar em risco sua fé religiosa. Impunham que as escolas católicas que praticassem por absoluta necessidade o sistema de classes mistas adotassem certas precauções, definindo normas rígidas e regras a serem seguidas para evitar perigos morais. Nesse ponto de vista se defendia um sistema de co-instrução no qual era destinada uma sala de aula para cada sexo. Estas se organizariam sob a mesma direção, possuindo uma só biblioteca e 
laboratório, aos quais meninos e meninas teriam acesso em grupos separados e horários diferentes. Com isso as despesas seriam reduzidas consideravelmente e não se adotaria a co-educação do ponto de vista comumente usado, obedecendo assim à orientação católica.

Essa visão estava claramente expressa na Acta Apostólica de 1930, veiculada num momento histórico em que a sociedade paulista demonstrava retomar valores católicos tradicionais com o ressurgimento do poder da Igreja. As precauções a serem tomadas, de acordo com a Acta Apostólica de 1930, seriam: que homens e mulheres religiosos e de postura superior poderiam julgar a necessidade da co-educação através da sua experiência moldada na religiosidade e amparada numa postura disciplinar proporcionada pela fé. Em todas as escolas, um diretor espiritual dirigiria a vida religiosa da instituição. Homens e mulheres religiosos raramente permitiriam o funcionamento de escolas mistas e somente em casos de extrema necessidade, devendo antes pedir permissão à sua Sagrada Congregação. Na escolha dos professores deveria ser assegurado que estes contribuiriam efetivamente para a educação moral e religiosa de meninos e meninas. O relacionamento dos dois sexos nas escolas, nos encontros sociais e nas atividades similares seria necessariamente pautado por procedimentos cristãos de moderação e modéstia e supervisionados por pessoal responsável de acordo com as circunstâncias, o local e o tempo. Eventos culturais e esportivos não constituiriam motivos para permitir que os dois sexos estivessem juntos, não devendo ser autorizados que compartilhassem espaços em comum. Haveria sempre de ter o cuidado de separar os sexos na sala de aula, onde ficariam meninos de um lado e meninas de outro; isso também se daria no horário de entrada e de saída, em banheiros, refeitórios e locais similares. Deveria haver classes especiais separadas quando certas lições de biologia e anatomia fossem dadas e houvesse leituras ou lições sobre o comportamento e a psicologia do outro sexo, ou quando cultura física ou jogos estivessem envolvidos. Era imperioso que a religiosidade e o bom comportamento coexistissem com o respeito no relacionamento mútuo. O único momento para o contato de todos seria durante as manifestações da fé e o ensino da religiosidade, o que deveria ser feito com dignidade e moderação (Acta Apostolicae Sedis, 1959, p. 21).
Nos anos 20/30 do século 20, a Igreja Católica se engajaria na luta por um maior espaço na educação com a intenção de adquirir maior controle social sobre a população. Os católicos consideravam que havia muitos problemas na educação originados da Reforma Protestante e até mesmo da Revolução Francesa, apontando o fosso profundo que separava o ensino laico do ensino religioso católico. O laicismo teria provocado a separação entre educação e instrução e, por conseqüência, entre o homem e o cidadão. Restabelecendo o elo com a educação religiosa, restabelecer-se-ia o ensino humanista voltado para as reais necessidades da sociedade. Nessa sociedade, onde os seres eram separados por sexo, não havia lugar para uma educação que eliminasse essa divisão natural.

Nas décadas de 30 e 40, um dos grandes detratores da co-educação foi o padre Leonel Franca, que, abordando os aspectos psicológicos, higiênicos e morais, apontava o equívoco de se educar juntos seres tão diferentes desses pontos de vista. Ao tentar demonstrar as peculiaridades e as diversidades entre os dois sexos, utilizava uma leitura androcêntrica ao alocar à mulher o desempenho de sua função natural, a maternidade. Ser mãe era "...uma missão educadora, uma missão de caridade". Esse argumento havia sido exaustivamente utilizado pelo pensamento católico do período, com Pio XI em 1929 e Pio XII em 1943. Alceu Amoroso Lima, católico convicto, iria utilizar atributos essencialmente diferenciados para os sexos: o homem era revolucionário, autoritário, político, belicoso, heróico, inteligente e especulativo; a mulher era conformista, conservadora, teimosa, econômica, tenaz, paciente, servidora da vida, possuidora de inteligência prática e intuitiva. Essas disparidades não seriam consideradas na co-educação, motivo pelo qual esta era antinatural, ao formar homens efeminados e mulheres masculinizadas, em inversões que seriam desastrosas para o equilíbrio social (Souza, s.d.).

O padre Leonel Franca, ao se opor ao regime co-educativo, apelaria para razões de ordem higiênica que visavam sexos diferentes, razões calcadas na maternidade para as mulheres e na paternidade para os homens, adotando os princípios do movimento higienista. Segundo ele, os anos iniciais da infância não apresentariam inconveniência de juntar meninos e meninas, mas na puberdade e adolescência isso 
deveria ser repelido em vista da sexualidade. Para a conservação da saúde da mulher e conseqüentemente para a saúde da futura prole, seria benéfico que a sociedade e o ambiente escolar mantivessem os sexos separados. Os motivos morais se ancoravam no perigo de relaxamento dos costumes e na corrupção do caráter, perigos que também estavam presentes nas exibições cinematográficas, nos romances, nos folhetins, nas fotos e no espaço das ruas. Os outros motivos apontavam para os problemas de convivência nas escolas, dado que os meninos possuíam mais poder e as meninas teriam mais a perder nessa relação que não era igual.

\section{A co-educação e o missionarismo protestante norte-americano}

Na virada do século 19, na visão dos intelectuais paulistas, os Estados Unidos eram a nação mais representativa de progresso e liberalismo democrático e seu exemplo apontado como sinônimo de país que se ergueu do caos de uma longa e sangrenta guerra civil e que foi reconstruído, tendo por meta a liberdade. E por liberdade a nação brasileira estava ansiosa; afinal, ainda eram recentes os tempos monárquicos. Por isso, não é de se estranhar que os protestantes tenham recebido apoio republicano para instalar suas escolas e que estas tenham sido tomadas como exemplo para as reformas do ensino que teriam lugar após a Proclamação.

Para os segmentos progressistas norteamericanos, o fato de meninos e meninas serem educados juntos na família era o principal argumento para defender a instituição de escolas mistas. Estas já proliferavam nas pequenas cidades americanas, onde o número de alunos era limitado. Porém, nas grandes cidades, escolas maiores organizavam classes separadas para os dois sexos e nas escolas privadas havia classes para meninos e meninas, a não ser que fossem crianças muito pequenas, o que esclarece a noção equivocada de que a co-educação fosse uma prática amplamente utilizada em todas as camadas sociais.

A chegada dos primeiros missionários protestantes na província de São Paulo, por volta de 1870, e a criação das pequenas escolas ao lado das igrejas e de colégios nas localidades maiores trouxeram ao panorama educacional uma concretização do que já acontecia nos Estados Unidos acerca da instituição da co-educação dos sexos. Os missionários norte-americanos, em que se considerem as idéias democráticas e libertárias de que estavam imbuídos, eram movidos pelas medidas de economia de investimentos físicos e recursos humanos, porém tinham um discurso ideológico compatível com as lutas feministas que se processavam no seu país acerca da igualdade de oportunidades educacionais para os dois sexos.

Desde a Guerra da Independência nos Estados Unidos, as escolas norte-americanas mostraram uma tendência em adotar o sistema de educar juntos os dois sexos. Em São Paulo os republicanos viam com bons olhos uma prática também compatível com o seu pensamento liberal e democrático. Se no Império, apesar do confronto com o regime monárquico, a Igreja Católica ditou as regras educacionais, na República os protestantes tiveram seu momento de glória, e a organização democrática de suas escolas era vista como exemplo a ser seguido pelo Estado na causa da educação popular. As razões econômicas que nos estados norteamericanos faziam com que muitos defendessem o funcionamento de classes mistas se escudavam na necessidade sempre presente de ampliar a escolarização no novo país que se desenhava no final do século 19 e que precisava de mentes ilustradas para prosperar. Porém, nas cidades onde havia maior número de habitantes e prosperavam escolas freqüentadas por crianças de todas as classes sociais, se organizavam classes separadas para meninos e meninas, especialmente se houvesse benefícios e não prejuízos nessa classificação:

Coeducation was instituted in America on economical grounds, as in thinly populated districts it was found that the number of pupils was too small to admit of separate schools being provided for boys and girls. (...) in some of the larger cities, as the schools grew large, and were composed of children gathered from all classes of society, it was often deemed best to organize separate boys' and girls' schools, especially as this could be done without injury, but possibly with a benefit to the classification (Hawtrey, 1896, p. 41).

A princípio, para os estadunidenses, a criação e o funcionamento das classes mistas foram determinados mais por problemas de ordem econômica do que por uma firme 
crença no seu efeito educativo. Posteriormente, essas classes foram aceitas por algumas parcelas da população como o melhor caminho para educar crianças e jovens. Pais e educadores passaram a acreditar que escolas de um só sexo poderiam obstruir o desenvolvimento de relações positivas entre meninos e meninas, dado considerarem que os dois sexos deveriam aprender a viver e trabalhar juntos, o que conduziria a casamentos felizes. Nas escolas separadas objetavam que meninos e meninas poderiam adquirir noções equivocadas sobre o sexo oposto e se manteriam os estereótipos. Discutia-se que fora da escola as crianças estavam engajadas largamente em atividades sexualmente segregadas, imitando os papéis reservados à mãe ou ao pai. Nas escolas mistas, ao terem a oportunidade de observar e conviver com o outro sexo, também poderiam aprender uns sobre os outros.

A passagem da discussão sobre classes mistas para a co-educação dos sexos foi rápida devido às reivindicações feministas do período, cujas expoentes consideravam as classes mistas a chance de oferecer às meninas a mesma educação que aos meninos, fornecendo a estas maiores oportunidades educacionais e a possibilidade de poderem exercer uma profissão, o que lhes traria mais liberdade individual. Argumentavam que a co-educação poderia perfeitamente bem conviver com as diferenças entre homens e mulheres e que esta deveria ser ampliada para além do simples agrupamento dos sexos nas escolas, indo em direção ao futuro social da convivência entre os sexos e estender suas concepções para além dos muros escolares em busca de uma verdadeira igualdade. Para as feministas existia nas classes mistas apenas o procedimento imediato de colocar juntos os dois sexos nos bancos escolares, porém na vida futura se mantinham separados pelas barreiras impostas no espaço social e pelas regras morais restritivas quanto às mulheres. Nas escolas mistas o que havia era uma co-instrução, e as escolas que se queriam co-educativas deveriam ir além dessa concepção.

Isso deslocou o enfoque da discussão apenas quanto aos fatores de ordem econômica e atraiu outros simpatizantes do sistema co-educativo. Esses segmentos, possuidores de uma visão liberal e democrática quanto à educação feminina, entendiam que a separação dos sexos nas escolas criava uma situação irreal e que as classes mistas tinham mais probabilidades de sucesso do que as de um só sexo. Alguns, entretanto, concordavam que esse procedimento seria mais aceitável na escola primária do que na secundária, utilizando praticamente os mesmos argumentos dos defensores da moralidade e dos bons costumes. Portanto, em que se considerem as firmes intenções equalizadoras dos defensores das classes mistas, as diferenças naturais continuavam se sobrepondo a quaisquer modismos e inovações quanto à educação feminina, tornando a possibilidade de mudanças sociais bastante remotas quanto à igualdade entre os sexos, o que instaurava um paradoxo quanto às expectativas sociais e os objetivos educacionais correspondentes. O espírito de justiça que imperava em toda sociedade democrática, ao considerar as mulheres iguais aos homens, deveria também lhes conceder a mesma educação e a mesma cultura, objetavam os educadores progressistas, pois, se futuramente a vida se revelasse difícil, as mulheres poderiam adquirir sua independência pelo trabalho digno e honesto. Tal premissa já evidenciava indícios de mudança de mentalidades ao não mais se rejeitar com tanta veemência o trabalho remunerado feminino, conforme norma de conduta seguida desde a Colônia.

Nos Estados Unidos e em outros países, o debate sobre a co-educação na primeira metade do século 19 levou governantes e entidades particulares a atenderem as aspirações femininas de educar os sexos em conjunto. No Brasil, em contrapartida, no caso paulista, a influência católica impediria sua disseminação entre as elites e a classe média, reservando essa modalidade apenas para as filhas dos segmentos populares, o que se confrontou com os mesmos ideais tão veementemente pregados pelos liberais republicanos. Em São Paulo, apesar da reputação das escolas americanas, as oligarquias não veriam com bons olhos suas filhas em classes mistas, e os colégios católicos continuaram, durante todo o século 19 e prolongando-se pelo século 20, oferecendo ensino em escolas e classes separadas para meninos e meninas, preparando cada sexo para ocupar distintas posições na hierarquia social.

\section{Considerações finais}

A ausência de investimentos e de profissionais do ensino, além da baixa densidade demográfica nas regiões interioranas onde cresciam as pequenas vilas e povoados, impedia a concretização do ideal católico de 
manter os sexos separados. No contexto citadino de São Paulo e na pobreza cultural e material da província, ainda era precário o sistema de ensino formal. Na cidade, nos anos 70 do século 19, a iluminação a gás, os carros de boi, a primeira linha de bonde, algumas casas comerciais, significavam pequenos lustros de progresso, num ambiente de higiene precária, promíscuo e de pouco lazer. No interior, com a população fortemente concentrada na zona rural, as vilas e povoados careciam de quaisquer benfeitorias, e a criação de classes para meninos e meninas obedecia a regras de pouca oferta e baixa procura. A distância da casa à escola era outro sério obstáculo para a família que desejava que seus filhos ou filhas estudassem. Nesse meio intelectualmente pobre, a escola não se colocava como prioridade e se abriam classes de duração efêmera, com funcionamento irregular e baixa freqüência; quase sempre havia um único professor, diferentemente da capital, com maior índice de população, o que permitia colégios de meninos e meninas, mas para aqueles que podiam arcar com os custos da educação, já que a maioria pertencia à iniciativa particular.

No âmbito do Estado, na idealizada escola laica, pesavam as restrições das famílias, e o poder público se debatia com a necessidade de estender a escolaridade para toda a população ampliando a abertura de classes e mantendo juntos os alunos e alunas dos segmentos populares, conforme a disponibilidade de espaço físico, investimentos financeiros e professores. Portanto, no século 19, o sistema público de ensino contava com classes mistas mais por força de circunstâncias econômicas do que acatamento de ideais co-educativos - e se instaurava uma dicotomia. O ideal republicano de apagar as diferenças sociais através da educação se via esvaziado perante a necessidade de escolas para a população e as dificuldades orçamentárias do Estado, e instalar classes mistas era o meio mais rápido de atender às urgências de escolaridade que a República reclamava.

A Inspetoria Geral da Instrução Pública do Estado de São Paulo, criada em 1852, apontava em relatório de 1870 a existência de trezentas e quarenta e seis cadeiras de instrução pública para o sexo masculino; duzentas e oito cadeiras para o sexo feminino, num total de nove mil e catorze alunos e cinco mil duzentas e trinta e três alunas; cinqüenta e nove escolas particulares para ambos os sexos, com mil trezentos e vinte e um alunos; e vinte e cinco colégios de instrução secundária com oitocentos e setenta e oito alunos (Marques, 1980, p. 343). A cidade de Rio Claro, no interior de São Paulo, por exemplo, contava em 1876 com doze mil duzentos e três habitantes e possuía quatro cadeiras de instrução primária pública para ambos os sexos, um colégio de instrução elementar e três escolas particulares (Moacyr, 1942, p. 211).

Apesar de haver na província várias escolas particulares e algumas pertencentes às instituições religiosas, o governo oferecia apenas o ensino elementar público e gratuito. A idéia de escolas mistas, com aulas regidas por professoras onde não fosse possível criar classes para ambos os sexos, orientava a criação e o funcionamento do ensino num cenário no qual o pensamento educacional republicano, aberto à livre iniciativa, comungava com as propostas de coexistência de instituições públicas e privadas. Esse ideário teve prolongamento após a República, tanto que, em memória apresentada ao governador Jorge Tibiriçá em 1891, Caetano de Campos assegurava: "é óbvio que ninguém pensará em tolher aos cidadãos o direito de abrir escolas particulares. Estas não serão, porém, em número suficiente para a população e nem acessíveis para a grande massa do proletariado" (Moacyr, 1942, p. 90). Sendo insuficiente o número de professores, era inviável a separação dos sexos, pois isso permitia, em caráter excepcional, a criação de classes mistas. Entretanto, isso não significava uma intenção eminentemente coeducativa de acordo com a concepção já discutida desta ser total, tanto que o Regulamento do Ensino em 1893 orientava que "as professoras das escolas mistas devem promover, durante os exercícios escolares, completa separação entre alunos e alunas, exercendo a mais ativa vigilância para não se dar qualquer procedimento desrespeitoso de uma para outra classe, procurando, com todo o cuidado, habituá-los a tratarem-se com polidez" (Moacyr, 1942, p. 192).

Ao mesmo tempo se impedia meninos de se matricularem nas escolas preliminares femininas e meninas nas masculinas, permitindo apenas nas escolas mistas a freqüência de ambos os sexos. Quando o regulamento instituiu a obrigatoriedade de ensino para crianças que não tinham aulas em casa ou que não estavam estudando em escolas particulares, foi colocado o limite em doze anos de idade, excetuando os meninos que residissem a mais de dois quilômetros da escola 
e as meninas que morassem a mais de um (Moacyr, 1942, p. 212). Isso fazia com que a obrigatoriedade de ir à escola não se estendesse à população rural, a não ser que fossem criadas classes nessas localidades. As escolas mistas correspondiam em grande número de casos às necessidades do ensino nos centros agrícolas onde havia pouca demanda por educação escolar em vista da baixa densidade populacional e deveriam ser ocupadas por professoras que "comumente serão mais zelosas e assíduas no cumprimento de seus deveres. Raríssimas foram as escolas mistas visitadas pelos inspetores, de freqüência diminuta" (Moacyr, 1942, p. 106).

No interior paulista, o ambiente provinciano e a imagética ligada às tradições faziam que os pais e a população em geral se posicionassem contrários ao agrupamento dos dois sexos nas escolas. De acordo com as normas sociais vigentes, o encontro de homens e mulheres somente deveria se dar através do casamento, onde dois seres criados separados deveriam adaptar-se um ao outro e viver juntos até que a morte os separasse, conforme ainda reza a liturgia católica nos tempos atuais. O fato é que as escolas mistas eram freqüentadas apenas por meninas dos extratos sociais desfavorecidos, e, mesmo assim, os pais as retiravam das escolas logo que aprendiam os rudimentos da leitura e escrita, o que fazia com que se fechassem classes por baixo comparecimento de alunas. ${ }^{6}$

O repúdio em educar juntos meninas e meninos tinha por base uma razão cultural representada por uma sociedade que se erigia em valores coloniais luso-cristãos, nos quais a instrução feminina era dispensável. Quando se instituíam classes mistas havia pressões ideológicas para a organização curricular, exigindo-se temas específicos para as meninas, como corte e costura, bordado, culinária, etc., o que resultava em currículos distintos para um mesmo grupo de alunos, horários de entrada, saída e recreio diferentes e até mesmo divisões físicas nas salas de aula. Algumas escolas para ambos os sexos no ensino primário e nos ginásios e escolas normais de São Paulo funcionavam a espaços, mas as classes mistas, desde algum tempo, eram uma realidade para a população mais pobre do interior, o que significa que a discussão de gênero levada pela Igreja e pelo Estado, numa luta conjunta pela moralidade da população, tinha um forte recorte classista, por esse discurso se referir às classes alta e média. Ao povo poder-se-ia fazer concessões, mesmo que com isso a moralidade e a religiosidade sofressem danos, porém a educação deveria ser estendida a todos, homens e mulheres, de diferentes classes sociais e raças. A co-educação, prática que se difundia nos demais países ocidentais, ajudaria a remediar os vícios do sistema escolar que se estruturava lentamente e carregado de defeitos e seria natural, vantajosa, imparcial, econômica e desejável.

Alguns defensores do ensino igual para os dois sexos argumentavam que as idéias de fragilidade e inferioridade que atribuíam às mulheres aqueles que se posicionavam contrários à co-educação significava uma postura arbitrária, pois, há mais de um século, tal processo estava se revelando eficaz nos Estados Unidos, na França, na Suécia e na Finlândia, entre outros. As mulheres possuíam suas faculdades intelectuais e criativas reprimidas devido à posição social que ocupavam e a uma educação tradicional que não desenvolvia sua inteligência e seu talento, retirando-lhes a possibilidade de se desenvolverem psíquica, intelectual e moralmente. Paradoxalmente, também se considerava que as diferenças naturais eram algumas vezes necessárias pelo fato biológico da reprodução (Meylan, 1904, p. 122).

No Brasil, apesar da separação da Igreja dos assuntos do Estado e da total proibição de ensino religioso nas escolas, há que se considerar a influência ideológica do catolicismo como a religião dominante entre a população. O matrimônio indissolúvel, os ritos do batismo, comunhão, crisma, extrema-unção impregnavam há mais de três séculos o imaginário brasileiro, e não seria o ato político de se depor um imperador português e instituir um regime republicano que ausentaria o povo desses rituais e de sua influência. A educação escolar não fugia disso, pois quem ensinava nas escolas também pertencia à população e vivia na sociedade brasileira fazendo parte do intenso intercâmbio cultural que a urbanização proporcionava, incorporando a imagética social do período quanto aos papéis sexuais.

Nas primeiras décadas após a República, a Igreja e o Estado não mais se alinhariam ideologicamente, e, ao apostar no poder transformador da educação para o futuro da nação que intentava se desenvolver e se alicerçar entre as grandes potências mundiais, esse projeto civilizador também alocaria

\footnotetext{
Rodrigues (1962, p. 170) relat que as primeiras escolas mistas de que se tem notícia datam de 1835, em Paranaguá e Ubatuba, onde existiam classes primárias mantidas por particulares. Em 1889, em Taubaté, existiam dois colégios mistos: Externato União, dirigido por José Ramos Ortiz, e Colégio Príncipe de Nápoles, de D. Elvira Colella, de origem italiana.
} 
à educação escolar o papel de equalizadora de oportunidades sociais. Desse princípio não se poderia alijar o sexo feminino do acesso à escola, e a democratização e universalização do ensino propostas também não deveriam permitir que esta fosse diferenciada da educação masculina. No entanto, na prática social e no mundo do trabalho, os papéis sexuais reservados a homens e mulheres confrontavam com essa tendência de maior igualdade entre os sexos, mostrando que nem sempre se processava o diálogo escolar com o diálogo social de forma harmoniosa e decorrente.

\section{Referências bibliográficas}

ACTA Apostolicae Sedis, 1930. In: FRISON, Basil. Co-education in the catholic schools. Roma: Institutum Iuridicum Claretianum; Boston: Daughters of St. Paul, 1959.

ACTAS e Pareceres do Congresso da Instrução do Rio de Janeiro. Rio de Janeiro: Typografia Nacional, 1884.

ALDRICH, R. Questões de gênero na História da Educação na Inglaterra. Educação em Revista, Belo Horizonte, n. 13, jun. 1991.

ANAIS do Museu Paulista. São Paulo, Tomo XV, 1961.

ANNAES da Conferência Interestadual de Ensino Primário. Rio de Janeiro: Ed. O Norte, 1922.

BARBOSA, R. Reforma do ensino primário e várias instituições complementares da instrução pública. Rio de Janeiro: Ministério da Educação e Saúde, 1947. (Obras completas; v.10, tomo III).

BRASIL. Lei Orgânica do Ensino Secundário. Portaria Ministerial n. 222, de 27/3/1943.

BRAZIL-MISSION (1833-1911). USA, Washington, Rand Corporation. (microfilmes-coleção-rolls $34,147,148,149)$.

CONFERÊNCIAS Populares da Freguesia da Glória no Rio de Janeiro, 1883. Microfilme.

HAWTREY, M. The co-education of the sexes. London: Kegan Paul, Trench, Triibner e Co. Ltda., 1896.

MARQUES, M. E. de A. Província de São Paulo: apontamentos históricos, geográficos, estatísticos e noticiosos. São Paulo: Edusp, 1980. v. 2.

MENDES, T. R. A Mulhér: sua preeminência social e moral segundo os ensinos da verdadeira sciência pozitiva. 4. ed. Rio de Janeiro: Igreja do Apostolado Pozitivista do Brasil, 1958.

MEYLAN, F. Th. La coéducation des sexes: étude sur l'education supérieure des femmes aux Etats Unis. Bonn: Charles Georgi, Imprimerie de l' Université, 1904.

MOACYR, P. A instrução pública no Estado de São Paulo: primeira década republicana 1890/1893. São Paulo: Cia Editora Nacional, 1942.

MUÑIZ, B. M. Sicologia de la coeducación. Madri: Edita Zero, 1970.

REVISTA ILLUSTRAÇÃO. Paris, v. 6, n. 22, p. 334, nov. 1889. 
REVISTA DE ENSINO. São Paulo, 1902, 1903, 1912.

REVISTA DO PROFESSOR. São Paulo, v. 1, n. 1, p. 29, mar. 1934.

RODRIGUES, L. M. P. A instrução feminina em São Paulo: subsídios para sua história até a proclamação da República. São Paulo: Faculdade de Filosofia "Sedes Sapientiae", Escolas Profissionais Salesianas, 1962.

SÃO PAULO (Estado). Governo do Estado. Anuário do Ensino do Estado de São Paulo. São Paulo, 1907/1908; 1911/1912; 1918.

SIMONTON, A. Diário-1852/1867. São Paulo: Casa Editora Presbiteriana, 1982.

SOUZA, C. P. de. Os caminhos da educação masculina e feminina no debate entre católicos e liberais: a questão da co-educação dos sexos, anos 30 e 40. In: PESQUISA histórica: retratos da educação no Brasil. Rio de Janeiro: UERJ, [s/d.]

TYACK, D.; HANSOT, E. Learning together: a history of coeducation in American Schools. New York: Yale University Press, 1990.

Jane Soares de Almeida, doutora em Educação pela Universidade de São Paulo (USP), é professora do Programa de Pós-Graduação em Educação da Universidade Metodista de São Paulo e professora colaboradora do Programa de Pós-Graduação em Educação Escolar da Faculdade de Ciências e Letras da Universidade Estadual Paulista (Unesp/Araraquara).

janeal@uol.com.br

\section{Abstract Co-education and mixed classes? Indicators for} school historiography (São Paulo - 1870-1930)

The article examines the education in São Paulo (1870/1930), through the discussion about the mixed classes and the ambiguity of legislators who were entrusted of manifesting on the co-education of the sexes. Some of them defended such practice; others condemned it using moral arguments headed towards Catholic precepts, in opposition to the Protestant principles that firstly introduced it in its schools, what demonstrates that the separation of Church and State in the recently implanted Republic was not always a reality in daily life.

Keywords: co-education of the sexes; women's education.

Recebido em 6 de julho de 2004.

Aprovado em 26 de agosto de 2005. 